\title{
When does math anxiety in parents and teachers predict math anxiety and math achievement in elementary school children? The role of gender and grade year
}

\author{
Monika Szczygieł ${ }^{1}$ (1)
}

Received: 8 June 2019 / Accepted: 20 May 2020 / Published online: 12 June 2020

(c) The Author(s) 2020

\begin{abstract}
The study investigated the relationship between math anxiety in parents and teachers and math anxiety and math achievement in first- to third-grade children. The results indicate that math anxiety in fathers (but not mothers and teachers) is associated with math anxiety in first-grade children and third-grade girls. Math anxiety in mothers and teachers (but not fathers) explains the level of math achievement in third-grade children. The research results indicate the importance of adults in shaping pupils' math anxiety and math achievement, but these relationships vary depending on gender and the grade year. The obtained outcomes generally suggest that adults' math anxiety is not a social source of children's math anxiety, but it can be considered a source of low math achievement among children in the final grade of early school education.
\end{abstract}

Keywords Math anxiety $\cdot$ Math achievement $\cdot$ Early school age $\cdot$ Parents $\cdot$ Teachers

\section{Introduction}

\subsection{Predictors and development of math anxiety and achievement}

Math skills are mentioned in the recommendations of the European Parliament and the Council of the European Union $(962 / \mathrm{EC} / 2006,2006)$ as one of the key competences in the process of lifelong learning. They are also considered a key area of STEM education (Gonzalez and Kuenzi 2012; Holmlund et al. 2018). Early school experiences in learning mathematics are very important for the future development of children's skills in this area (Levine et al. 2010). It is important to understand the factors that predict differences in the level of math achievement in elementary

Monika Szczygieł

monika.szczygiel@up.krakow.pl

1 Institute of Psychology, Pedagogical University of Krakow, ul. Podchorążych 2, 30-084 Kraków, Poland 
school children. This is because difficulties in math learning may even appear at the very beginning of education (Jordan et al. 2006). The determining factors for math achievement in children include the following individual variables: biological (Tosto et al. 2014), cognitive (Kyttälä and Lehto 2008; Sasanguie et al. 2013), emotional (Wu et al. 2012), and personality (Li and Kun 2007). There are also environmental variables: related to culture (Phillipson and Phillipson 2007), family (BlevinsKnabe and Musun-Miller 1996; Phillipson and Phillipson 2007; Sirin 2005), and school (Lorenzen 2017; Maxwell et al. 2017). Math anxiety in children (Harari et al. 2013), their parents (Maloney et al. 2015), and teachers (Widmer and Chavez 1982) is considered to be an important predictor of math achievement, both individually and environmentally. According to Richardson and Suinn (1972, p. 551), "math anxiety is a feeling of tension and anxiety that interferes with the ability to manipulate numbers and to solve mathematical problems in both ordinary life and academic situations." Finding out and understanding the sources of math anxiety is desirable because of its importance in predicting math achievement (Cargnelutti et al. 2016; Vukovic et al. 2013a).

Until recently, the onset and development of math anxiety were believed to be closely related to the level of difficulty experienced during mathematical task completion and the accumulation of failures in this area (Hembree 1990; Jameson 2014; Maloney and Beilock 2012). In his meta-analysis, Hembree (1990) demonstrated that math anxiety varies in level across age groups: it is low or medium in elementary school children; it peaks in the high school period, and slowly falls after graduation (but continues to exist). Nevertheless, the math anxiety development model by Hembree (1990) did not include the results of studies involving early school children because these have only been conducted in recent years. The results of recently conducted studies show that early school children, although having little experience related to mathematics, also feel a certain level of math anxiety (e.g., Cargnelutti et al. 2016; Ramirez et al. 2013, 2016). Generally, the average level of math anxiety in children is low or moderate, but some individual children experience an extremely high level of math anxiety (Cargnelutti et al. 2016). The increasing number of research results confirm the existence of math anxiety in early school children and the relationship between their math anxiety and math achievement (e.g., Ramirez et al. 2013; Wu et al. 2012). These research outcomes have contributed to investigations into the sources of pupils' math anxiety that extend beyond the difficulty of mathematical tasks and the accumulation of failures.

Studies on the determinants of math anxiety are conducted in various areas. Researchers mention the following factors as sources of math anxiety: (1) cognitive factors (weak number sense, Lindskog et al. 2017); (2) personality factors (low math self-esteem and low math self-efficacy, Jameson 2014); (3) social factors (gender and math stereotypes, Beilock et al. 2010; Cheryan et al. 2015; math anxiety or negative attitude toward mathematics in teachers and parents, Hadley and Dorward 2011; Jameson 2014; traditional teaching methods, Lorenzen 2017; insufficient parental involvement in children's math learning, Gunderson and Levine 2011; Levine et al. 2010; Vukovic et al. 2013b); and (4) factors related to the nature of mathematics (the abstract nature of mathematics, the need to remember many rules, high or excessively high levels of difficulty experienced during math problem completion, 
failures in math learning; Mason 1988). Unresolved problems and controversies can be found in each and every research area investigating the emergence and development of math anxiety; however, they are particularly pronounced in the social area.

It is especially interesting to explore the social sources of pupils' math anxiety and math achievement: more specifically, the effect of adults' own math anxiety on children's math anxiety and math achievement. Researchers (e.g., Aslan et al. 2013; Lindskog et al. 2017; Sovchic 1996) indicate the importance of math anxiety levels in parents and early school teachers for shaping children's math anxiety and their level of math achievement, but they often do not provide sufficient evidence to confirm this thesis. Although parents' and teachers' math anxiety is commonly believed to be a significant factor in explaining children's math anxiety and achievement, few studies have been carried out to check these relationships. For this reason, a study was planned to ascertain whether children's and adults' math anxiety levels are directly or indirectly related to each other, and whether adults' math anxiety can be a factor that predicts children's math achievement. This issue is worth exploring, which is best evidenced by the fact that information about whether teachers or parents "infect children with math anxiety" appears in the literature (e.g., Burton 1979). This finding in turn would suggest that reduced math anxiety in parents and teachers implies a lower level of math anxiety in children. However, if math anxiety in adults is not directly related to children's math anxiety and their math achievement, it is necessary to look for other sources of pupils' math anxiety and low achievement or to look for mediating and moderating factors that explain the impact of adults' own math anxiety on children's math anxiety and achievement. It is important to explore the significance of adults' own math anxiety in explaining children's math anxiety and achievement. It is vital both from a theoretical perspective (investigations into factors explaining the mechanism of the onset and development of math anxiety) and a practical point of view (the need, or lack thereof, for appropriate interventions to reduce math anxiety levels in adults).

Having these problems in mind, the first aim of this article is to present current studies about the relationship between parents' and teachers' own math anxiety and children's math anxiety and math achievement. The outcomes of previous studies on this topic will be discussed in detail below. This is because research plans and their outcomes are extremely diverse in this area. Such an organization of material can also facilitate the understanding of the factors that may be key to elucidating the relationship between parents' own math anxiety and math anxiety and achievement in children. The second objective of the paper is to explain why I have decided to conduct a study on the topic and discuss my research findings regarding Polish early school children, their parents, and teachers.

\subsection{The importance of the family environment}

The importance of parental factors in children's educational outcomes has been revealed in many studies (Blevins-Knabe and Musun-Miller 1996; Simpkins et al. 2005, 2006; Sirin 2005), and it is not surprising that researchers see agents in the family that predict the intensity of children's math anxiety and the level of their 
math achievement. Many authors (e.g., Harari et al. 2013; McLeod et al. 2007) have reported empirical evidence that parenting practices play a role in developing and maintaining children's anxiety. However, few studies have been carried out to check the relationships between parents' and children's math anxiety and pupils' math results. Table 1 presents current research in this area.

Maloney et al. (2015) examined whether parents' math anxiety can be used as a predictor for first- and second-grade children's math achievement. It turned out that only math anxiety in those parents who help their children do homework predicts the math outcomes of children, but there is no such relationship when high-mathanxiety parents do not help them (Bhanot and Jovanovic 2005; Maloney et al. 2015). The level of parents' math anxiety did not predict children's achievement in reading, which suggests that the influence of their anxiety is specific to mathematics. Parents with a high level of math anxiety have the opportunity to express negative emotions related to mathematics when helping their children with math homework (Bhanot and Jovanovic 2005). This can decrease the motivation of these children to learn the subject, and thus leads to their under-achievement in math and increased math anxiety. Maloney et al. (2015) reveal the importance of parents' math anxiety in predicting children's performance, but they do not confirm the hypothesis of a direct relationship between the math anxiety of parents and children. The model explaining the relationship between the variables included in this study is the following: math anxiety in parents who help children with homework determines the math achievement of children, and the level of children's achievement predicts their level of math anxiety.

Other findings include those by Jameson (2014), who determined the role of personal and environmental factors that predict math anxiety in second-grade children. In the first model, which includes children's personal characteristics (gender, math self-concept, and math self-efficacy), only math self-concept turned out be a significant predictor of children's math anxiety. The second model, which, in addition to personal characteristics, also included parents' variables (math anxiety, the frequency of math activity at home, and the accessibility of math activities at home), revealed the importance of three variables: children's math self-concept, children's math self-efficacy, and the frequency of math activity at home. Irrespective of the tested models, math self-concept is the strongest predictor of math anxiety in children, and parents' math anxiety was not a significant predictor of children's math anxiety.

The results of a study carried out by Soni and Kumari (2017) among older children, from fifth to tenth grade, show a direct relationship between the math anxiety of children and that of their parents. According to the authors, there is a relationship between math anxiety in parents and children, and the math anxiety of children predicts their math achievement. This relationship, unlike the one observed in the study by Maloney et al. (2015), occurs regardless of parental help with children's homework.

Casad et al. (2015) reported results from two studies conducted among children aged 11-14 years. They checked whether children's math anxiety and parents' math anxiety (and the interaction between these variables and gender dyads) predict children's math self-efficacy, math outcomes (GPA), math behavioral intentions, math 


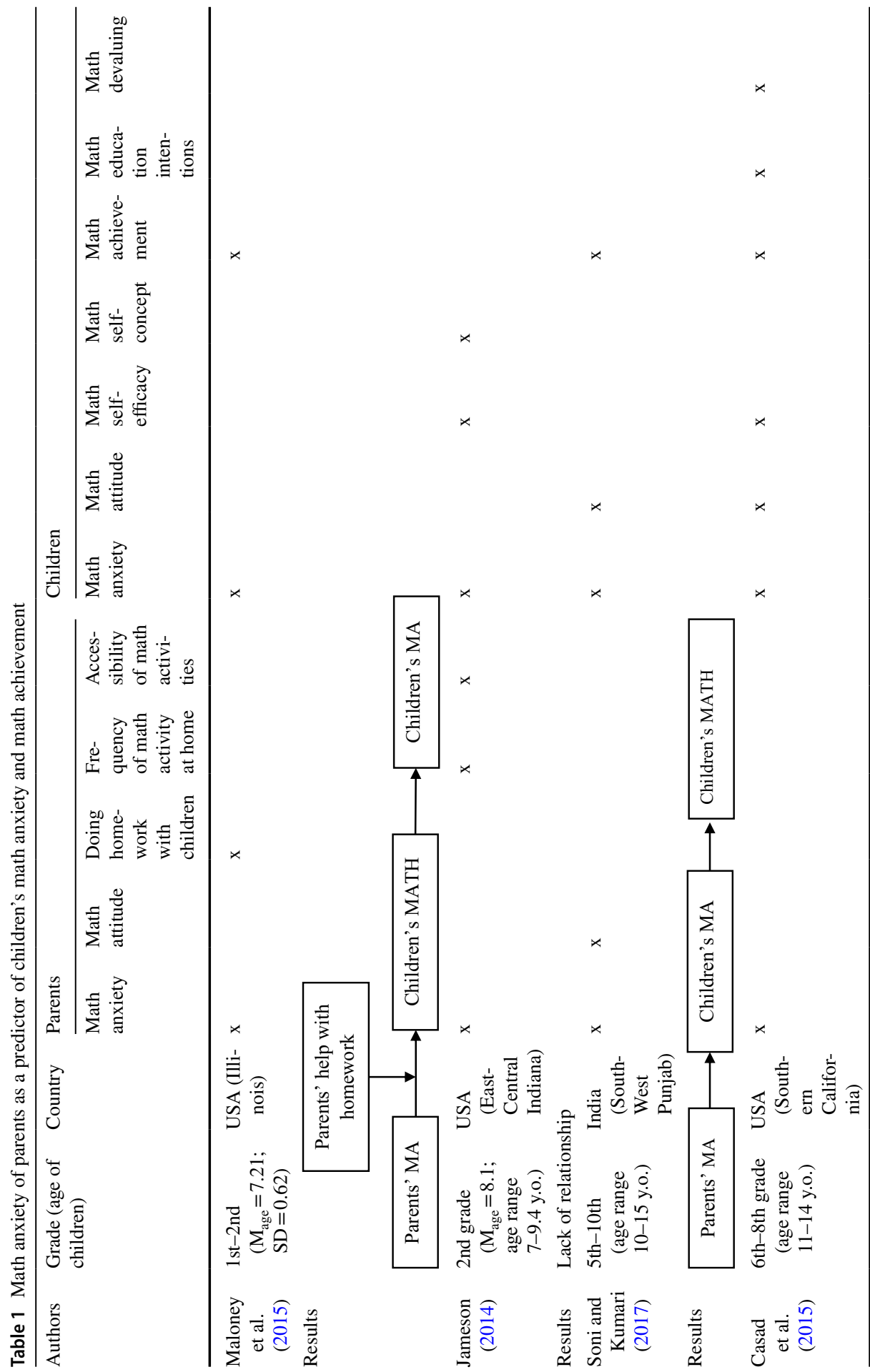




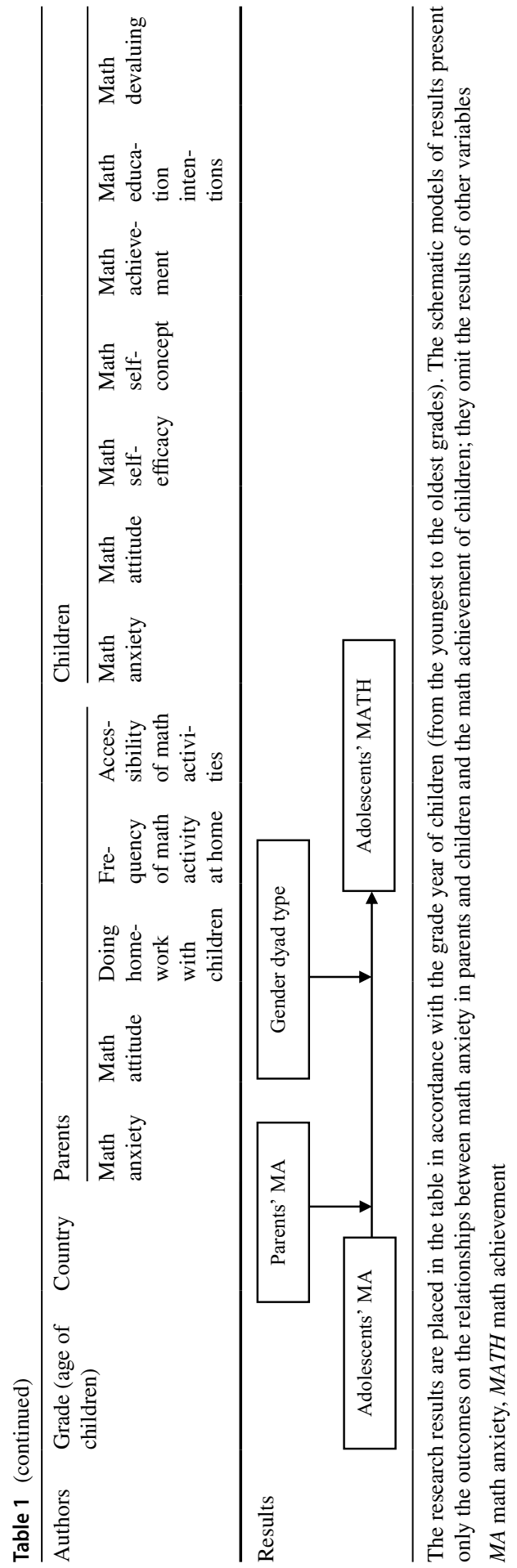


attitudes, and the devaluing of math as a subject of study. Many hypotheses were tested by the authors, but the most important findings for this paper are the results indicating the role of math anxiety in parents and children and their gender dyad type in explaining all children's math-related variables. The analysis of the interaction model indicates that there is a relationship between the math performance of adolescents with low math anxiety and the low math anxiety of parents (especially in mother-daughter dyads).

Summing up the results, two studies have indicated the relationship between parents' math anxiety and that of their children (Casad et al. 2015; Soni and Kumari 2017), and two studies have failed to do so (Jameson 2014; Maloney et al. 2015). In Soni and Kumari (2017) study, math anxiety in parents predicts children's math anxiety but not their math achievement. Maloney et al. (2015) observed the opposite: parents' math anxiety predicts children's math achievement but not their math anxiety. Casad et al. (2015) did not check the direct relationship between parents' anxiety and that of their children, but they observed a correlation between these variables. Jameson's (2014) study did not confirm the relationships between parental math anxiety and children's math anxiety or math achievement. Additionally, all of this research highlights the importance of different factors (parents' gender, help with homework, and education stage) that play a role in the relationship (and the relationship's direction) between math anxiety in parents and math anxiety and achievement in children.

Research results are yet to provide a definite answer to the question of the role of parents' math anxiety in predicting children's math anxiety and achievement, or the conditions in which this variable influences children's emotions and reduces achievement. Therefore, it is not legitimate to claim that parents directly transfer their math anxiety to their children, and thus influence their math achievement. Although previous findings have generally shown that the role of parents in shaping children's math anxiety and performance is important, more studies on this topic (that would take into account such factors as gender and grade year) are definitely needed to understand social factors that underlie children's math anxiety and achievement. If math anxiety in parents is the source of math anxiety and low mathematical achievement in children, parents should be provided with appropriate interventions to prevent the emergence and development of math anxiety in children. Otherwise, it is necessary to look for other sources of math anxiety in youngest pupils.

\subsection{The significance of math anxiety in teachers}

Similar to family factors, the sources of children's math anxiety and low mathematical achievement can also be sought in teachers. The widespread belief that teachers' math anxiety causes high math anxiety and low math achievement in pupils is a result of several interrelated premises: (1) math anxiety is more widespread and more intense in women than men (Drudy 2008; Hernik et al. 2014), and the majority of teachers are women ( $>90 \%$ in the USA; Beilock et al. 2010; almost 99\% of early school teachers in Poland; Malinowska et al. 2014); (2) the level of math anxiety in pre-service teachers is higher than in other groups of 
students in higher education (Hembree 1990; Szczygieł and Cipora 2016); (3) in most countries, prospective early school teachers do not have to meet many requirements in the field of mathematics (Malzahn 2002), which results in low levels of mathematical knowledge and poor quality teaching methods (Beilock et al. 2010; Harper and Daane 1998); (4) teachers with a high level of math anxiety may be oriented toward immediate and observable results and, therefore, use direct instruction more often (Harper and Daane 1998; Lorenzen 2017). This can decrease pupils' math achievement and increase their math anxiety (Jacobsen and Lehrer 2000).

However, the research findings presented above do not indicate a direct relationship between teachers' math anxiety and students' math anxiety and math outcomes. Studies that have tested the relationship between teachers' math anxiety and children's math outcomes are rare, and their results seem to undermine the hypothesis that teachers' math anxiety has a universal impact on the level of math achievement in learners. What is more, probably no research to date has tested the relationship between children's math anxiety and that of their teachers. A summary of previous studies on this topic is presented in Table 2.

Aslan et al. (2013) conducted a study in which they measured the math anxiety and math-related beliefs of teachers and the mathematical achievement of pre-school children. The results of their study indicate that math achievement is higher in those preschoolers who are assisted by teachers with positive rather than negative beliefs about mathematics; however, the high or low level of teachers' math anxiety does not reveal such differences in their learners' math performance. The authors did not measure children's math anxiety in the study.

A study that confirms the belief about the role of teachers' math anxiety in the math achievement of early school children was conducted by Beilock et al. (2010). The authors measured the math anxiety and math stereotypes of teachers and the gender ability beliefs and math achievement of children. The study was conducted in the first and second grade of elementary school. At the beginning of education, there was no relationship between the level of math anxiety of teachers and the level of math achievement of pupils. At the next measurement, it turned out that teachers with a high level of math anxiety had transferred their stereotypical beliefs to girls, but not to boys. The girls who believed in stereotypical gender differences in math achievement were inferior in math performance to girls who did not believe in this stereotype; they were also inferior to boys regardless of whether the latter believed or not in the gender stereotype. The results of the study are consistent with the claims of Bussey and Bandura (1984) and Perry and Bussey (1979), i.e., that children are more likely to imitate the behavior and attitudes of adults of the same gender. However, the study did not measure children's math anxiety. Therefore, it did not show whether teachers' math anxiety affected pupils' math anxiety.

A study conducted among older children (from first to sixth grade) and their teachers was carried out by Hadley and Dorward (2011). The study measured math anxiety, math teaching anxiety, and math teaching methods in teachers and math achievement in children. It turned out that there is a relationship between teachers' math-teaching anxiety and children's math performance, but this correlation was very weak $(r=0.09, p<.05)$ and practically negligible. In the study, no relationship 


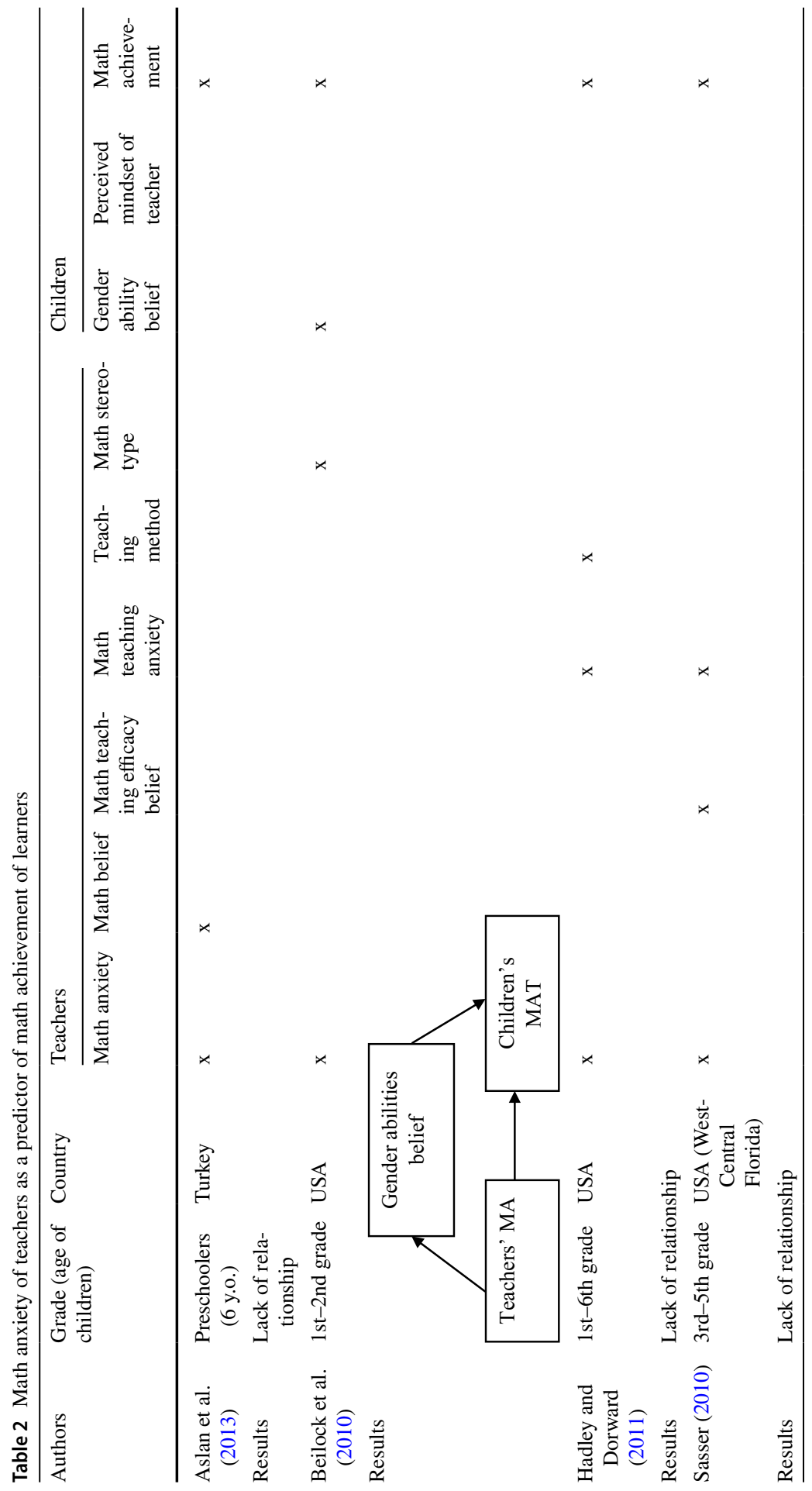




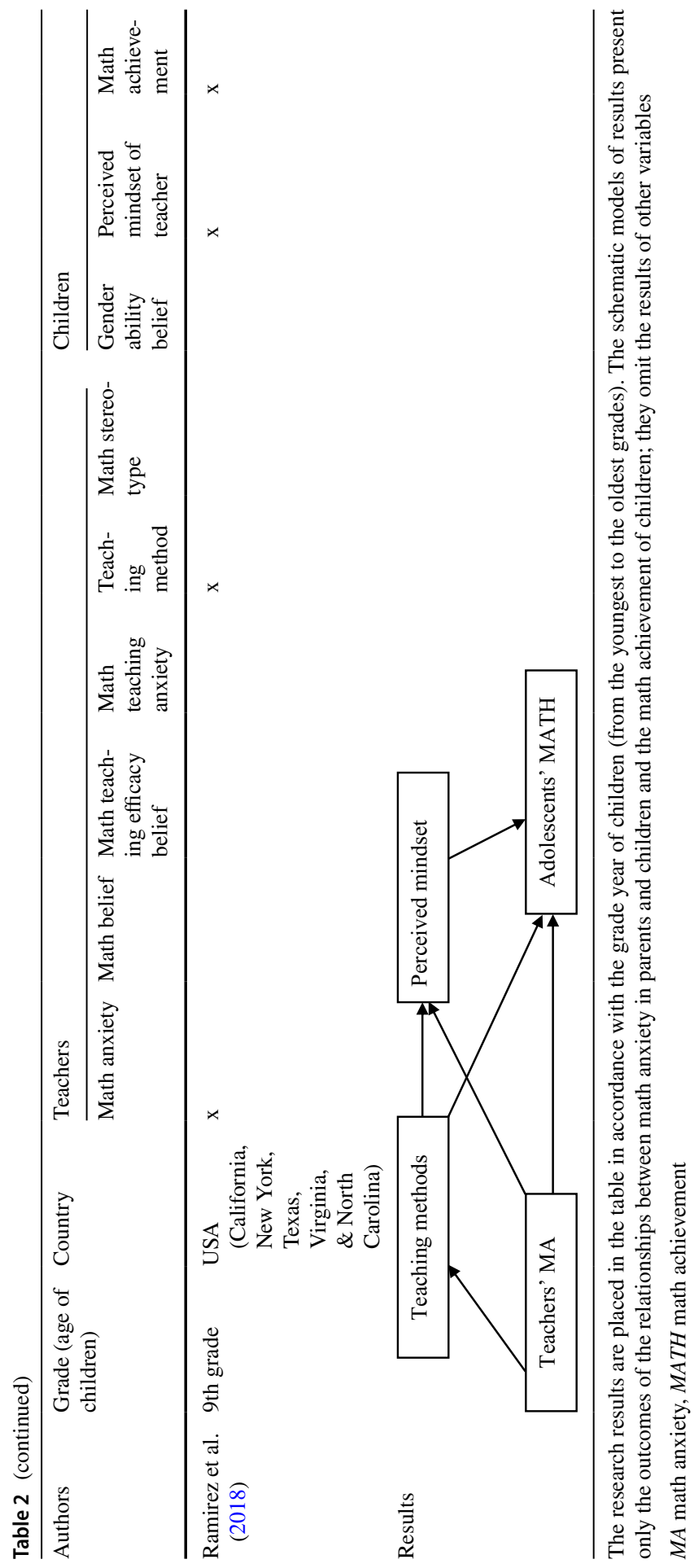


was observed between teachers' math anxiety and pupils' math achievement. Similar to the studies described above, the authors did not measure children's math anxiety.

Sasser (2010) described the results of children from the third to fifth grades and their teachers; she analyzed the relationship between math anxiety, math teaching anxiety, and math teaching efficacy beliefs of teachers and the math achievement of pupils. The results indicate that only teachers' belief about their own effectiveness was associated with the math results of their pupils. Math anxiety in teachers did not correlate with the performance of children. Again, the math anxiety of children was not checked.

A study on the importance of teachers' math anxiety in predicting ninth-grade students' math performance was undertaken by Ramirez et al. (2018). The researchers modeled the relationships between teachers' math anxiety and teaching methods and students' perceptions of teachers' mindsets and math achievement. It was shown that teachers' math anxiety directly and indirectly (mediated by other variables) affected children's math achievement. The researchers did not check the level of math anxiety in pupils and its relation to teachers' math anxiety.

Summing up, there has been little direct evidence to date showing that math anxiety in teachers determines math anxiety and achievement in children. In two of the aforementioned studies, a relationship between teachers' math anxiety and children's math achievement was observed (Beilock et al. 2010; Ramirez et al. 2018), but in the others no such relationship was confirmed (Aslan et al. 2013; Hadley and Dorward 2011; Sasser 2010). Additionally, it is not known whether there is a relationship between teachers' math anxiety and that of children because none of the discussed studies tested this hypothesis. Determining whether there is a direct relationship between teachers' math anxiety and that of children makes it possible to verify the common belief that math anxiety in teachers influences the occurrence and development of math anxiety in children and affects their math outcomes. If math anxiety and achievement in children could be predicted with teachers' math anxiety, this means that one of the sources of math anxiety in students and their low math achievement is teachers' math anxiety. This could justify the application of anxiety-reducing interventions among pre-service and early-school teachers. If there is no relationship between teachers' and children's math anxiety, and teachers' math anxiety and pupils' math achievement, then the sources of math anxiety and low math outcomes should be sought in other factors: social, cognitive, personalityrelated, and those related to the nature of mathematics.

\subsection{Present study}

The main purpose of the study is to verify the hypothesis regarding the importance of parents' and teachers' math anxiety in predicting the math anxiety and math results of early school children. Previous studies included various variables that could be relevant to explaining this relationship, but when looking at all the results, there was not enough attention paid to the mechanisms of math anxiety formation in early childhood. The choice of the research group is justified by the fact that early school children are particularly prone to endorsing the behavior and beliefs of adults 
(Beilock et al. 2010). Early school children may be especially prone to endorsing the stereotypical math and gender beliefs of parents and teachers of the same gender (Beilock et al. 2010; Cheryan et al. 2015; Steffens et al. 2010), but relatively little attention to date has been paid to the gender factor as a possible explanation of the relationship between adults' and children's math anxiety and adults' math anxiety and children's math achievement. Additionally, the type of education is one of the important factors that may explain the role of teachers and parents in shaping children's math anxiety and low math achievement: teachers in early school education are not mathematicians and much evidence suggests that their math anxiety may be important in explaining children's math anxiety and achievement levels. The majority of parents may have difficulty helping children with math homework because they are not educated in this area (Goodall and Johnston-Wilder 2015). Taking these factors into account, the following questions and hypotheses were formulated:

Q1: Is parents' and teachers' math anxiety related to children's math anxiety?

H1: The higher the level of math anxiety in (a) mothers, (b) fathers and (c) teachers, the higher the level of math anxiety in children.

Q2: Is gender a moderator of the relationship between math anxiety in children, parents, and teachers?

H2: Gender is a moderator between the level of math anxiety in (a) mothers, (b) fathers, and (c) teachers and children's math anxiety.

Q3: Is parents' and teachers' math anxiety related to children's math results?

H3: The higher the level of math anxiety in (a) mothers, (b) fathers, and (c) teachers, the higher the level of math achievement in pupils.

Q4: Is gender a moderator of the relationship between math anxiety in parents and teachers and math achievement in children?

H4: Gender is a moderator between math anxiety in (a) mothers, (b) fathers, and (c) teachers and the math performance of children.

\section{Methods}

\subsection{Participants}

The study was conducted in nine public elementary schools in Krakow (Poland) among early school children, their parents, and teachers. The schools occupy different positions in the ranking of schools in the city (at the top, middle, and bottom of the scale). Two hundred and forty-one pupils took part in the research: 46 children (23 girls) from the first grade, $M_{\text {age }}$ (range) $=7$ years and 3 months (6.1-8.3 years); 101 children (60 girls) from the second grade, $M_{\text {age }}($ range $)=8$ years and 2 months (7.1-9.3 years); 94 children (51 girls) from the third grade, $M_{\text {age }}$ (range) $=9$ years and 4 months (8.0-11.2 years). The research was also conducted among parents who consented to their child's participation in the study (in several cases both parents filled out the questionnaires). In total, 176 mothers and 51 fathers participated in the study. Most families were characterized by a relatively high socio-economic status (income, education, and occupation). Thirty early school education teachers 
(women) agreed to participate in the project. The mean duration of their teaching experience was around 20 years and 6 months (18 years in the current position). In Poland, there are four levels of professional advancement for a teachers (first levelnew teacher, fourth level-master grade). The teachers were high in professional competence: seventeen teachers held the fourth and highest professional rank, nine of them held the third, four were at the second level, and none were at the beginning of their career path.

\subsection{Materials}

\subsubsection{Math Anxiety Questionnaire for Adults (MAQA)}

Math anxiety in adults is usually measured with the AMAS (the Abbreviated Math Anxiety Scale; Hopko et al. 2003), MARS (the Mathematics Anxiety Rating Scale; Richardson and Suinn 1972), MARS-R (Plake and Parker 1982), and sMARS (Alexander and Martray 1989). However, these scales mostly measure math anxiety in the school context (e.g., taking a math examination, being given a "pop" quiz in math class, being given a difficult homework assignment that is due at the next lesson), which seems to be an inaccurate way to measure math anxiety in adults who are no longer learning mathematics.

To resolve these problems, a new school-independent questionnaire was created to measure the level of math anxiety in adults. The questions were selected following the math anxiety definition by Richardson and Suinn (1972). As a result, the content of the questions relates to the solving of various mathematical tasks. The first aim of the constructed questionnaire was to avoid questions about past experiences related to math teachers, math classes, or math examinations; the second objective was to check the current level of math anxiety in adults when in contact with simple mathematical tasks. The Math Anxiety Questionnaire for Adults (the MAQA) includes 19 simple math problems (e.g., calculating the average fuel consumption of a car, calculating the surface area of a sphere) and is unidimensional. The MAQA is presented in full in "Appendix 1". Participants assessed their level of math anxiety on a four-point scale: 1-I definitely do not feel anxiety, 2-I generally do not feel anxiety, 3-I feel some anxiety, 4-I definitely feel anxiety. The indicator of math anxiety is the average score of all items; the higher the average score, the higher the level of math anxiety.

The validity and reliability of the scale were checked in a series of pilot studies ( $N=359$ adults). The MAQA correlated positively both with the AMAS ( $r=0.63$, $p<.001$; the Polish language version of the Abbreviated Math Anxiety Scale; Cipora et al. 2015), and the SIMA ( $r=0.66, p<0.001$; the Single-Item Math Anxiety Scale; Núñez-Peña et al. 2014), and correlated highly negatively with math attitudes $(r=-0.71$ to $-0.75, p<.001$; the Math Attitudes Scale for Adults; MASA; paper under review). The MAQA scores are moderately correlated with trait anxiety $(r=0.25-0.27, p<.001)$ and weakly correlated with state anxiety $(r=0.18-0.21$, $p<.001$; the State-Trait Anxiety Inventory; STAI; the Polish language version Spielberger et al. 2011). The associations between the MAQA and the history of grades 
obtained at school (elementary, junior high school, and high school) and the results of the high school-leaving examination in Polish and Mathematics (the basic and extended level) were checked. The MAQA scores do not correlate with grades in Polish (at all educational stages) and do not relate to the final Polish examination (the basic or advanced level). However, the MAQA results are negatively related to grades in Mathematics and the results of the high school-leaving examination in Mathematics $(r=-0.31$ to $-0.52, p<.001)$. Additionally, the MAQA results correlated negatively with math self-esteem $(r=-0.57)$, but did not correlate with Polish language self-esteem. These data provide arguments for the specificity of the MAQA in the measurement of math anxiety. When constructing the questionnaire, no specific structure of its items was assumed, but exploratory and confirmatory factor analyses were carried out which confirmed the following assumption: the MAQA is unidimensional. Summing up, the convergent and divergent validity was established in the validation studies. The very good reliability of the scale was also confirmed: the internal consistency varied between $\alpha=0.91$ and 0.95 in the pilot studies and $\alpha=0.94$ in the present study. The test-retest reliability calculated by Pearson's $r$ was $0.85(N=69)$.

\subsubsection{Math Anxiety Questionnaire for Children (MAQC)}

Based on the Mathematics Anxiety Scale in Young Children (MASYC; Harari et al. 2013) and the Scale for Early Mathematics Anxiety (SEMA; Wu et al. 2012), a new inventory was constructed to measure children's math anxiety. This is because the original scales produced a number of problems during pilot studies. Children had difficulties assessing their emotions on a four or five-point scale as well as understanding the instructions and questions; also, there were problems adapting the math questions to the conditions of the Polish system of education. Taking these problems into account, the instructions were simplified (Please, tell me) and a three-point response scale was used ( $2-Y e s, 1-A$ little, $0-N o$ ). The indicator of children's math anxiety is the average score of all items. The higher the score on the MAQC, the higher the level of math anxiety ( 0 - lack of math anxiety, 1 -moderate level of math anxiety, 2-high math anxiety). The items were transformed into a semistructured interview (e.g., When you are in math class and the teacher says that you will be discussing a new topic, are you nervous?); the final version of the inventory consisted of fourteen items (see "Appendix 2").

The psychometric properties of the MAQC were checked in another study conducted among elementary school children. The convergent validity was confirmed by correlating the MAQC results with the mAMAS-E results (the modified Abbreviated Math Anxiety Scale for Elementary School Children, Szczygieł 2019; based on the mAMAS, Carey et al. 2017): $r=0.60, p<.001(N=157)$. Divergent validity was satisfactory: the MAQC scores moderately, $r=0.52, p<.001(N=61)$, correlated with the RCMAS results (the Revised Children's Manifest Anxiety Scale; Stark and Laurent 2001; Reynolds and Richmond 1978). The test-retest reliability of the MAQC is satisfactory but quite low, $r=0.56, p<.001(N=55)$. To assess the theoretical validity in the pilot and final studies, exploratory and confirmatory factor analyses were additionally performed and the results reveal that the scale is 
unidimensional. The MAQC's reliability in the final study was $\alpha=0.76$ for children of both genders in all grades (first grade $\alpha=0.68$, second grade $\alpha=0.75$, third grade $\alpha=0.79$ ) and is acceptable.

\subsubsection{Math achievement (MATH)}

The math tasks were prepared using the core curriculum for elementary schools and mathematical books recommended by the Polish Ministry of Education. The difficulty of each task was assessed: the level of easiness was expressed by the ratio of points actually scored by children compared to the maximum points that could be obtained. The interpretation of this coefficient is the following: $0.00-0.19$ very difficult, 0.20-0.49 difficult, 0.50-0.69 moderately difficult, 0.70-0.89 easy, 0.90-1.00 very easy (Janowicz 2017). In the present study, the average level of difficulty for the math test was 0.77 for first grade, 0.71 for second grade, and 0.71 for third grade. Thus, the mathematical tasks used in the study can be defined as "easy" or "moderately difficult."

The tests examined the practical application of mathematical knowledge in the following areas: knowledge of numbers, counting, addition and subtraction, discovering rules, knowledge of money, knowledge of geometric figures, reading a tape measure (first grade); addition and subtraction, multiplication and division, reading a tape measure, spatial orientation, discovering rules, clock reading (second grade); addition and subtraction, multiplication and division, reading a tape measure, discovering rules, clock reading, knowledge of dates and money (third grade). The maximum score that could be obtained in the tasks in each grade was 36 .

\subsection{Procedure}

Ethical permission was obtained from the Scientific Research Ethic Committee of the Institute of Psychology, Jagiellonian University of Krakow. The investigation was conducted on the school premises after prior approval from heads of schools and pupils' parents. The study was conducted in three groups: children from first to third grades, their parents, and their teachers. The data from parents were collected before the research among children started; measurements among teachers were conducted in parallel with the first measurements among pupils. The second testing session began after the first meeting with all children in the school. The data were collected by four researchers who had previously been trained in the research procedure.

Parents who took part in a parent-teacher conference consented to their own and their child's participation in the study and completed the MAQA. The same questionnaire was also completed by teachers. Teachers who filled out a consent form to participate in the study were assured that the collected data were confidential, and were informed that they could withdraw their consent if they wished to do so. The present study is part of a larger research project in which individual and environmental predictors of children's math anxiety and achievement were tested. The children were tested individually in two rounds. The first and second testing sessions 
took place in April-May and May-June, respectively. During the first meeting, intelligence, working memory, number sense, and math anxiety were assessed; in the second meeting, mathematical achievement was measured. The average times of the first and second testing sessions were about $25 \mathrm{~min}(15-45 \mathrm{~min})$ and $35 \mathrm{~min}$ (10-45 $\mathrm{min})$, respectively. The average interval between the two meetings was 47 days. The time of both measurements depended on the individual pace of the child's work. Before the study, the children were informed about the purpose of the meeting; they were also assured that they could withdraw from the study at any time. The children were aware that they could ask any questions of the researcher and say if something was not clear to them. To eliminate the impact of the children's varying levels of reading skills, the instructions were read aloud by the researcher.

\subsection{Analysis}

Firstly, descriptive statistics were presented and then two-level hierarchical linear models were prepared in the $R$ package: lmerTest 2.0-36 (Kuznetsova et al. 2017). Compared to the linear regression model, hierarchical regression is a more advanced method of data analysis and allows a more reliable estimation of clustered data. All analyses were carried out according to the same scheme: at first, it was checked whether it was necessary to include the random effect of the teacher or whether the grouping of students in the grade was sufficient to provide an accurate assessment of the relations between variables; subsequently, the appropriate model was created. In some cases, the number of children included in the analysis was smaller than the size of the research sample; this is because some children refused to perform some tasks or adults provided incomplete questionnaires. The data were divided into grade years because of different math tasks used in the study. Despite the fact that the same number of points could be obtained in each grade, the same score had a different meaning for first-, second- and third-grade pupils. Performing analysis without fitting a separate regression slope for each grade year would require adding the interactive effects of grade year. To simplify the presentation of the results, the statistical effects for mothers, fathers, and teachers were presented separately.

\section{Results}

\subsection{The intensity of math anxiety and math achievement scores}

The descriptive statistics were calculated in the first step of analysis. Table 3 presents the number of participants, range, mean, standard deviation, skewness and kurtosis of math anxiety, the math achievement of children, and math anxiety in adults.

The mean level of math anxiety in elementary school children was low, and most of the results indicated a lack or low level of math anxiety in first- to third-grade children. In the case of adults, the greatest dispersion of results was observed among mothers, slightly less in teachers, and the least among fathers. Mothers had either a low or moderately high level of math anxiety (a few of them admitted to extremely 
Table 3 Descriptive statistics of math anxiety and math achievement in children and adults

\begin{tabular}{lrrrrrr}
\hline & $N$ & Range & Mean & $S D$ & Skewness & Kurtosis \\
\hline $\begin{array}{l}\text { Math anxiety } \\
\text { Children }\end{array}$ & & & & & & \\
1st grade & 46 & $0-1.07$ & 0.36 & 0.28 & 0.98 & 0.34 \\
2nd grade & 101 & $0-1.43$ & 0.33 & 0.29 & 1.54 & 3.16 \\
3rd grade & 94 & $0-1.71$ & 0.34 & 0.32 & 1.78 & 4.16 \\
Mothers & 160 & $1-4$ & 1.98 & 0.66 & 0.52 & -0.19 \\
Fathers & 48 & $1-2.72$ & 1.69 & 0.53 & 0.38 & -1.15 \\
Teachers & 28 & $1-2.95$ & 2.04 & 0.62 & -0.05 & -1.43 \\
Math achievement & & & & & \\
Children & & & & & & \\
1st grade & 46 & $6-35$ & 27.75 & 4.98 & -2.01 & 6.95 \\
2nd grade & 101 & $12.5-35$ & 26.17 & 5.51 & -0.43 & -0.71 \\
3rd grade & 93 & $5-36$ & 25.67 & 7.33 & -0.80 & 0.21 \\
\hline
\end{tabular}

Possible range of math anxiety results of children is 0-2 and of adults is $1-4$; possible range of results in math achievement is $0-36$

high math anxiety). Most fathers rated their level of math anxiety as low (only a few reported a moderate level of math anxiety). In the group of teachers, some of them felt low math anxiety and the rest experienced a moderate level of negative emotions. Summing up, most of the children and adults did not feel or experience mild math anxiety, but some of them did feel strong or extremely strong anxiety. In the case of mathematical tasks, the mean results and distribution indicated a relatively high level of math achievement in the whole group.

\subsection{Math anxiety in parents, teachers and children}

In the next part of the analysis, it was checked whether there is a relationship between math anxiety in mothers, fathers, teachers, and children using a two-level hierarchical regression model (see Table 4). In the first step of the analysis, models that included the fixed effect of mothers' and fathers' math anxiety on children's math anxiety were tested. In these cases, only the grouping of students in classes was controlled, and the random effect of the teacher was not assessed. To check the analogous relationship between teachers' and children's math anxiety levels, the model additionally included the random effect of teachers (class effects).

First, it was checked whether children's math anxiety could be predicted by the math anxiety of their mothers. The results of the analysis revealed no relationship between math anxiety in mothers and math anxiety in learners. Thus, H1(a) was not confirmed. Nevertheless, hypothesis H1(b), which predicts a relationship between math anxiety in fathers and math anxiety in pupils, was partially confirmed. With a one-point increase in fathers' math anxiety, the level of math anxiety in first graders increased by 0.31 points $(p<0.05)$, but no such relationship was observed in other grades. Finally, it was checked whether there is a relationship between the 
Table 4 Math anxiety in adults and math anxiety in children

\begin{tabular}{|c|c|c|c|c|c|c|}
\hline & \multicolumn{2}{|l|}{ Mothers } & \multicolumn{2}{|l|}{ Fathers } & \multicolumn{2}{|l|}{ Teachers } \\
\hline & Estimation & $S D$ & Estimation & $S D$ & Estimation & $S D$ \\
\hline \multicolumn{7}{|l|}{ Fixed effects } \\
\hline 1st grade & $0.53 * *$ & 0.19 & -0.22 & 0.21 & -0.05 & 0.34 \\
\hline 2nd grade & $0.39 * * *$ & 0.11 & $0.61 * *$ & 0.19 & 0.28 & 0.12 \\
\hline 3rd grade & 0.24 & 0.13 & 0.17 & 0.23 & 0.19 & 0.13 \\
\hline MAQC 1st grade & -0.10 & 0.09 & $0.31 *$ & 0.12 & 0.16 & 0.14 \\
\hline MAQC 2nd grade & -0.03 & 0.05 & -0.18 & 0.11 & 0.03 & 0.05 \\
\hline \multirow[t]{2}{*}{ MAQC 3rd grade } & 0.06 & 0.06 & 0.12 & 0.13 & 0.07 & 0.06 \\
\hline & Variance & $S D$ & Variance & $S D$ & Variance & $S D$ \\
\hline \multicolumn{7}{|l|}{ Random effects } \\
\hline $\begin{array}{l}\text { Variance of class } \\
\text { effects }\end{array}$ & 0 & 0 & 0 & 0 & 0 & 0 \\
\hline Residual & 0.10 & 0.32 & 0.06 & 0.25 & 0.09 & 0.30 \\
\hline \multicolumn{7}{|l|}{ Model summary } \\
\hline REML & 99.6 & & 15.3 & & 117 & \\
\hline$N$ Children & 160 & & 48 & & 223 & \\
\hline$N$ Class & 31 & & 25 & & 28 & \\
\hline
\end{tabular}

$* * * p<.001 ; * * p<.01 ; * p<.05$

Dependent variable: children's math anxiety (MAQC), independent variable: adults' math anxiety (MAQA)

math anxiety of teachers and that of their students; however, this correlation was not observed, which undermines the validity of H1(c).

In the next step of the analysis, it was checked whether the gender of the children moderated the relationship between the math anxiety of mothers, fathers, and teachers and that of children (see Table 5).

The moderating role of children's gender in the relation between mothers', teachers' and children's math anxiety was not confirmed, which disproves hypotheses H2(a) and H2(c). However, hypothesis H2(b), which concerns the relationship between fathers' and children's math anxiety, was partially confirmed. This relationship is moderated by the gender of children, but only in the third grade. It was observed that a one-point increase in the level of math anxiety of fathers is related to a one-point increase in the math anxiety level of girls $(p<.05)$, but this relationship was not observed for boys. The summary of results on the math anxiety of adults and math anxiety of children is presented in Fig. 1.

\subsection{Math anxiety in parents and teachers and math achievement in children}

To test the influence of parents' and teachers' math anxiety on children's math achievement, a two-level hierarchical regression model was again used. Math achievement scores were standardized to achieve a better model fit to the data. In the first step of the 
Table 5 Gender moderation in children's and adults' relationships of math anxiety

\begin{tabular}{|c|c|c|c|c|c|c|}
\hline & \multicolumn{2}{|l|}{ Mothers } & \multicolumn{2}{|l|}{ Fathers } & \multicolumn{2}{|l|}{ Teachers } \\
\hline & Estimation & $S D$ & Estimation & $S D$ & Estimation & $S D$ \\
\hline \multicolumn{7}{|l|}{ Fixed effects } \\
\hline 1st grade & $0.57 *$ & 0.24 & 0.09 & 0.28 & 0.37 & 0.60 \\
\hline 2nd grade & 0.06 & 0.22 & $0.61 *$ & 0.22 & 0.16 & 0.18 \\
\hline 3rd grade & 0.30 & 0.20 & 0.43 & 0.40 & 0.19 & 0.17 \\
\hline MAQC × gender $(1$ st grade $)$ & 0.01 & 0.18 & 0.37 & 0.23 & 0.26 & 0.31 \\
\hline MAQC $\times$ gender $(2$ nd grade $)$ & -0.17 & 0.12 & -0.03 & 0.20 & -0.06 & 0.11 \\
\hline \multirow[t]{2}{*}{ MAQC $\times$ gender $(3$ rd grade $)$} & 0.10 & 0.13 & $1.00 * *$ & 0.35 & 0.03 & 0.12 \\
\hline & Variance & $S D$ & Variance & $S D$ & Variance & $S D$ \\
\hline \multicolumn{7}{|l|}{ Random effects } \\
\hline Variance of class effects & 0 & 0 & 0 & 0 & 0 & 0 \\
\hline Residual & 0.10 & 0.31 & 0.05 & 0.23 & 0.09 & 0.30 \\
\hline \multicolumn{7}{|l|}{ Model summary } \\
\hline REML & 106.7 & & 11.9 & & 129.3 & \\
\hline$N$ Children & 160 & & 48 & & 223 & \\
\hline$N$ Class & 31 & & 25 & & 28 & \\
\hline
\end{tabular}

$* * p<.01 ; * p<.05$

Dependent variable: children's math anxiety (MAQC), independent variable: adults' math anxiety (MAQA)

Fathers' MA $\longrightarrow 1^{\text {st }}$-grade children's and $3^{\text {rd }}$-grade girls' MA

Fig. 1 Summary of adults' and children's math anxiety relationships, $M A$ math anxiety

analysis, the impact of mothers, fathers and teachers on the math achievement of children was examined (see Table 6). All tested models assumed fixed effects of adults' math anxiety and possible differences in the effect of adults' math anxiety on the math achievement of pupils (these differences result from differences between teachers). Thus, the tested models also included the random effect of teachers (class effects).

First, the significance of mothers' math anxiety for predicting the math achievement of children was checked. The results showed that a one-point increase in the level of math anxiety in mothers is related to a decrease in the level of children's math performance of $0.41 S D(p<.05)$ in the third grade, which partially confirms H3(a). No relationships were observed among mothers and first and second graders. Next, the hypothesis that the math achievement of children would decline as a result of an increase in fathers' math anxiety was tested, but no significant relationships were discovered in any of the grades; therefore, H3(b) was not confirmed. However, the importance of teachers for predicting the math achievement of children was observed when the relationship between math anxiety in teachers and the 
Table 6 Math anxiety in adults and math achievement of children

\begin{tabular}{|c|c|c|c|c|c|c|}
\hline & \multicolumn{2}{|l|}{ Mothers } & \multicolumn{2}{|l|}{ Fathers } & \multicolumn{2}{|l|}{ Teachers } \\
\hline & Estimation & $S D$ & Estimation & $S D$ & Estimation & $S D$ \\
\hline \multicolumn{7}{|l|}{ Fixed effects } \\
\hline 1st grade & 0.17 & 0.57 & 0.12 & 0.66 & 0.73 & 1.38 \\
\hline 2nd grade & -0.36 & 0.35 & 0.72 & 0.60 & 0.19 & 0.55 \\
\hline 3rd grade & $0.72^{‘}$ & 0.41 & -0.42 & 0.74 & $1.25^{*}$ & 0.62 \\
\hline MATH 1st grade & 0.02 & 0.28 & 0.12 & 0.39 & -0.28 & 0.60 \\
\hline MATH 2nd grade & 0.18 & 0.18 & -0.41 & 0.36 & -0.11 & 0.29 \\
\hline \multirow[t]{2}{*}{ MATH 3rd grade } & $-0.41^{*}$ & 0.21 & 0.53 & 0.43 & $-0.62 *$ & 0.31 \\
\hline & Variance & $S D$ & Variance & $S D$ & Variance & $S D$ \\
\hline \multicolumn{7}{|l|}{ Random effects } \\
\hline $\begin{array}{l}\text { Variance of class } \\
\text { effects }\end{array}$ & 0.03 & 0.18 & 0.04 & 0.21 & 0.05 & 0.22 \\
\hline Residual & 0.83 & 0.91 & 0.54 & 0.74 & 0.77 & 0.88 \\
\hline \multicolumn{7}{|l|}{ Model summary } \\
\hline REML & 438.5 & & 113.5 & & 601.2 & \\
\hline$N$ Children & 158 & & 48 & & 222 & \\
\hline$N$ Class & 31 & & 25 & & 28 & \\
\hline
\end{tabular}

Dependent variable: children's math achievement (MATH), independent variable: adults' math anxiety (MAQA)

$* p<.05 ; " p<.1$

math performance of third graders was examined. A one-point increase in teachers' math anxiety was associated with a decrease in the level of math results by $0.62 S D$ $(p<.05)$ in third graders, but not in first or second graders. Thus, hypothesis H3(c) was partially confirmed.

The hypothesis on the role of gender moderation in predicting the impact of math anxiety in parents and teachers on children's results was tested; however, no such relationship was observed in any case. Therefore, hypotheses $\mathrm{H} 4(\mathrm{a}-\mathrm{c})$ were not confirmed (see Table 7, "Appendix 3"). The summary of the results for math anxiety in adults and math achievement in children is presented in Fig. 2.

In conclusion, elementary school children experienced a low level of math anxiety; however, adults had a greater variability of math anxiety and generally reported it in low or moderate levels. Only some of the hypotheses concerning the relationship between adults' math anxiety and children's math anxiety and math

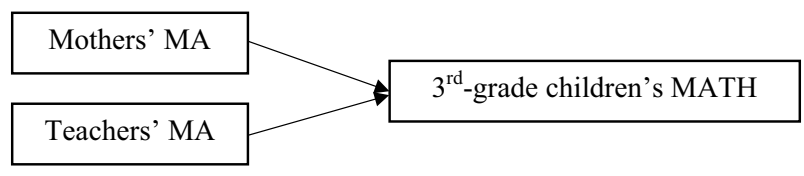

Fig. 2 Summary of adults' and children's math anxiety relationships, $M A$ math anxiety, $M A T H$ math achievement 
achievement were confirmed. Math anxiety in fathers was associated with math anxiety in first graders and third-grade girls, but it did not predict children's math achievement. The math performance of third graders, but not first and second graders, can be predicted by the math anxiety of mothers and teachers, but not fathers.

\section{Discussion}

\subsection{Adults' math anxiety as a predictor of math anxiety in children}

The study shows that math anxiety in mothers and teachers was not associated with that of children, while an increase in the level of math anxiety in fathers was moderately associated with an increase in math anxiety in first graders. The moderating effect of gender in the math anxiety of adults and children was observed only in third graders and fathers. An increase in the math anxiety of fathers is related to an increase in the math anxiety of girls, but no effect was observed for boys. This relationship can be described as strong. The obtained results are only partially in accordance with the outcomes of Casad et al. (2015) and Soni and Kumari (2017), who underlined the role of parents in predicting children's math anxiety.

It is interesting to ask why the math anxiety of fathers is associated with the math anxiety of children only in first- and third-grade girls, but not in second grade. This irregular relation pattern can be most reliably explained by the size of the group in which analysis was carried out: no more than twenty dyads were used to assess the relationship in each grade year. The obtained results should therefore be treated as a starting point for further research: in order to determine whether fathers' math anxiety is a source of children's math anxiety, it is necessary to conduct a study in a larger group of dyads. However, these are interesting results because, to date, neither theoretical models nor empirical studies have indicated fathers as a potential source of children's math anxiety. Among the environmental causes of math anxiety, the anxiety of early-school female teachers (Beilock et al. 2010) or mothers (Casad et al. 2015; Maloney et al. 2015) have been mentioned more often as a possible risk factor. The mechanism of math anxiety described by researchers assumes that women, especially early school teachers, feel strong math anxiety, which in turn may trigger math anxiety in students, mainly girls (Beilock et al. 2010).

In this study, the hypothesis about the importance of math anxiety in mothers and teachers in predicting children's math anxiety was not confirmed: neither when direct dependence was checked, nor when the effect of interaction with gender was taken into account. It is possible that the low level and variance of math anxiety in children and the low to medium level and variance of math anxiety in mothers and teachers are some of the reasons for the lack of a relationship between children's and mothers' math anxiety. Summing up, mothers and teachers do not transfer their math anxiety to children because their level of math anxiety is not very strong. Additionally, children from first to third grade experience weak math anxiety, so even if they generally do not feel math anxiety, it is difficult to diagnose factors that affect its level. Although early school children feel a certain level of math anxiety, this can be partly explained by pupils' general anxiety (Carey et al. 2017; Ganley and McGraw 2016). However, the lack of a relationship between mothers', teachers' and children's math anxiety undermines the common 
belief that teachers "infect" children with math anxiety (Burton 1979). Perhaps mothers' and teachers' math anxiety is important in the emergence of children's math anxiety, but this relationship is mediated by other variables, e.g., mathematical knowledge (Malzahn 2002), teaching methods (Hadley and Dorward 2011; Lorenzen 2017), stereotypical beliefs (Beilock et al. 2010; Jackson 2008), math homework help (Maloney et al. 2015), and involvement in education (Phillipson and Phillipson 2007).

In conclusion, the study mostly negatively verified the hypothesis that adults transfer their math anxiety to children. These results suggest that the mechanism of the emergence and development of children's math anxiety is complex. The results obtained among fathers should be treated with caution due to the small number of observations; however, the outcomes suggest that the relationship is not direct: gender and grade year are important factors that moderate this relationship. The obtained results also showed that early school children have low math anxiety levels (some students already feel intense math anxiety at the beginning of school, but this is a rare phenomenon), so the explanation of small differences in their math anxiety levels requires sensitive and reliable measures of both predictors of math anxiety and math anxiety itself. When looking for sources of math anxiety, one should also take into account other more general factors that may be significant: cognitive (number sense, Lindskog et al. 2017), emotional (general anxiety and test anxiety, Carey et al. 2017; Ganley and McGraw 2016), personality related (math self-esteem, math self-efficacy, Jameson 2014), social (parental involvement in children's education; Vukovic et al. 2013b; math-related beliefs of parents and teachers, Beilock et al. 2010; Bhanot and Jovanovic 2005), and mathematical (level of task difficulty, Maloney and Beilock 2012; Mason 1988).

\subsection{Adults' math anxiety as a predictor of children's math achievement}

The results indicate that math anxiety in mothers and teachers (but not fathers) directly predicts the math achievement of third-grade learners (but not first and second grade). The obtained results are partially in line with previous studies that revealed an interaction relationship between parents' math anxiety and children's math achievement (Casad et al. 2015; Maloney et al. 2015). Even stronger than in the mothers-children dyad, a direct relationship was also observed among teachers, which is in contrast with previous research that found a mediation relationship only (Beilock et al. 2010; Ramirez et al. 2018). However, it should be emphasized that although the math anxiety of mothers and teachers is directly related with children's math anxiety, such results appear only among pupils at the end of early school education. It seems, therefore, that the grade year should necessarily be included in the model in order to better estimate the effect of parents' and teachers' math anxiety on children's math achievement. To date, research has been conducted throughout various grade years (Aslan et al. 2013; Beilock et al. 2010; Casad et al. 2015; Hadley and Dorward 2011; Jameson 2014; Maloney et al. 2015; Ramirez et al. 2018; Sasser 2010; Soni and Kumari 2017), hence this variable may be one of the key factors that is crucial to understanding why previous research results differ from each other so much.

It is possible that math anxiety in teachers and mothers predicts the results of third graders, but not first and second graders, due to the increased difficulty of the math 
curriculum. Teachers and parents do not need to acquire expert knowledge and skills in mathematics to explain math problems to children starting school. However, in older grades, the curriculum is more complex, and problems are more advanced, which could be a challenge for non-math specialists. This is not to say that teachers or mothers do not have the capability to understand and master math problems, but rather they avoid conversations related to math, do not instigate math discussions, do not motivate children to seek their own solutions to tasks, are reluctant to analyze learners' unusual and creative math ideas, and have problems relating math tasks to everyday life (Goodall and Johnston-Wilder 2015). Hence, students learn ineffective strategies of coping with math problems, which in turn influences the level of their math achievement.

In the final evaluation of the model of the relationship between adults' math anxiety and children's math achievement, factors that explain the learning of behaviors should also be considered. It is possible that the math anxiety of adults affects children's achievement through the mechanism of modeling beliefs and behaviors (Bussey and Bandura 1984; Perry and Bussey 1979). In their study, Dotti Sani and Treas (2016) demonstrated that mothers spend more time helping children with their homework than fathers, which can be crucial in understanding why mothers' but not fathers' math anxiety predicts pupils' math achievement. Women have a higher level of anxiety than men (Drudy 2008; Hembree 1990; Hernik et al. 2014), and, according to Jackson (2008), a highly math-anxious person can cause children's low math achievement due to the beliefs they present about learning math: the belief in needing special mathematical abilities to be able to learn math, the conviction that there is only one set of correct ways to solve math problems, the belief that even working hard does not guarantee success in the field of math, and the conviction that math is useless. All these beliefs lead to the conviction that it makes no sense to take the trouble to learn math. In older grades, pupils can understand these types of beliefs and accept them whilst observing their own progress, successes, and failures.

In conclusion, the hypothesis regarding the prediction of pupils' math achievement based on adults' math anxiety was partially confirmed. The results of the study revealed the importance of math anxiety in mothers and teachers but only in predicting the math outcomes of children at the end of early school education. The results suggest that the gender of teacher and parents as well as grade year should be included in future studies that test the importance of social factors in explaining the level of math achievement in pupils. The study partially reveals the role of parents' and teachers' math anxiety. Therefore, one should also consider how to reduce this anxiety in a group of people teaching math at home or at school. However, it should be remembered that adults' math anxiety is a rather domain-specific predictor of students' math achievement and more general factors like teaching methods (Hadley and Dorward 2011; Lorenzen 2017) or parental involvement (Phillipson and Phillipson 2007; Vukovic et al. 2013b) may have a greater and more universal significance in explaining differences in students' math achievement.

\subsection{Limitations and further research perspectives}

The results require not only theoretical but also methodological and statistical discussion. It is also necessary to indicate paths for further investigations. The first 
problem concerns the number of participants in the study, especially the number of fathers. The results of the study show a significant role of fathers' math anxiety in predicting math anxiety in children, which is why it is important to conduct this type of study among a larger group of men. For practical reasons, it may be difficult to get both parents involved in the study. That said, the research results obtained so far offer important implications for undertaking this effort. It should also be emphasized that the study was attended by those learners who obtained consent to participate from their parents, so not all students from a given class were examined. The group of teachers was also small and consisted of women, but this is typical of studies carried out in schools (Beilock et al. 2010; Malinowska et al. 2014). It is important to note that not all teachers agreed to complete all questionnaires. The measurement of math anxiety can threaten the self-esteem of teachers and thus affect research results.

The second problem concerns the statistical methods used by researchers to analyze clustered data within classes and schools. Due to the clustering of students in classes and the dependence of their school results on factors related to the teacher, the best method for estimating the relations between variables is multi-level hierarchical regression analysis (Casad et al. 2015; Kuznetsova et al. 2017). However, this type of analysis makes it impossible to identify the direction of the relationship between variables. This analysis also requires a large number of observations.

The next problem to consider in the future is the type of math anxiety measurement. Many questionnaires have been developed to measure math anxiety in both adults and young children, and many of them are a modification of scales intended for testing school children or adolescents and measuring different types of math anxiety. Thus, a theoretical question arises about the theoretical validity of math anxiety measurements in the school context among adults who recently finished math education and the adequacy of measuring youngest children using self-report scales. It is possible that the relationship between the math anxiety of adults and children and the achievement of learners is dependent on the component of math anxiety, but so far data on the subject have been insufficient and fail to go beyond hypothetical considerations.

Finally, an important factor which should be considered in future research is the cultural context. Most of the studies on children's and adults' math anxiety and math achievement relationships were conducted in the USA. The significance of the specificity of the education system in different countries should be taken into account when generalizing research observations. Countries differ not only in the curriculum of mathematics in early school education, but also in the age at which school education begins, teaching objectives, and requirements for early childhood education teachers. Therefore, obtaining an answer about the universality of the relationship between the math anxiety of parents, teachers, and children and children's math achievement requires more research in different cultural, social, and political contexts.

\subsection{Practical implementation}

The problem of the intensity and prevalence of math anxiety is considered so important that in 2008 the United States' National Mathematics Advisory Panel recommended the development of effective interventions to counteract the emergence and development of 
math anxiety (U.S. Department of Education 2008). Hence, the question of whether math anxiety in parents and teachers predicts the level of children's math anxiety and their achievement is important not only for theoretical but also practical reasons. It is widely believed that math anxiety in teachers and parents has a negative impact on the math anxiety and achievement of children. Therefore, appropriate interventions to reduce this anxiety have been tested (e.g., Berkowitz et al. 2015). This study does not provide conclusive evidence that math anxiety in parents and teachers predicts the math anxiety and achievement of early school children in a universal and direct way, but the results do confirm the importance of pupils' grade year and the gender of both children and parents as important factors that explain the relationship between tested variables. Thus, the study partially revealed the importance of applying appropriate interventions for reducing parents' and teachers' math anxiety. What if parents do feel math anxiety? One easy solution is to use math applications to help children learn mathematics. Highly math-anxious parents could use an app to obtain adequate help without revealing their negative emotions in relation to mathematics (Berkowitz et al. 2015). Governments should also run social campaigns promoting the development of children's math skills through parent-child math talk and math games from the earliest years of children's lives.

It should be noted that there are probably many intermediary factors that affect the existence of this relationship, i.e., between adults' math anxiety and children's math anxiety and math achievement. Therefore, these factors should also be examined when planning interventions aimed at reducing children's math anxiety and developing their math achievement. Although many studies indicate the role of parents' involvement in children's math achievement (Gunderson and Levine 2011; Levine et al. 2010; Vukovic et al. 2013b), many parents believe that their role in shaping the math outcomes of their children is very small compared to the responsibility of the school (Cannon and Ginsburg 2008; Maloney et al. 2015). Making parents more aware of the fact that they primarily influence attitudes toward math and math achievement may increase the level of children's achievement and make their math experience more positive.

In the present study, teachers were characterized by a low to medium level of math anxiety, but it should be remembered that this was enough to affect the math achievement of third graders. The role of teachers' math-related emotions and attitudes should also be taken into consideration because their feelings toward math are closely related to their beliefs and teaching practices (Minarni et al. 2018). The problem of high levels of math anxiety is common in many countries (Hembree 1990; Szczygieł and Cipora 2016), so it is important to implement appropriate solutions when recruiting university students and to carry out proper interventions to reduce math anxiety during university studies. One effective method of reducing math anxiety in future teachers, although somewhat controversial, is to teach them teaching methods, not mathematical content (Harper and Daane 1998; Took and Lindstrom 1998). Cognitive-behavioral methods which can be recommended for pre-service and practicing teachers include the reinterpretation of physiological arousal (Jamieson et al. 2010), expressive writing (Park et al. 2014), and mindfulness training (Brunyé et al. 2013). Teacher's math anxiety may affect children's math outcomes. For this reason, teachers' mathematical knowledge, beliefs about the nature of mathematics, math-gender 
stereotypes, math self-efficacy, and math self-esteem should also be taken into account when preparing teachers for teaching practice.

\section{Conclusion}

Despite the widespread belief that math anxiety in parents and teachers affects the math anxiety and achievement of children, the results of this study did not provide conclusive evidence to support this thesis. Particularly questionable is the hypothesis about the transfer of adults' math anxiety to children. The results generally show that math anxiety in parents and teachers does not always transfer to children. The father-children math anxiety relationship needs more investigations that include different grade years and gender dyads to understand the nature of this link. More reliable evidence was gathered for the thesis about the importance of adults' math anxiety in predicting the math achievement of children. Math anxiety in adults predicts the math achievement of children if the gender of the adults and children's grade year are considered.

The results of the study are an argument for the thesis that the formation mechanism of math anxiety and math achievement is complex and cannot be reduced to a simple transfer of math anxiety from adults to children. The observed role of adults' math anxiety in predicting the math achievement of children, despite the fact that it depends on the children's grade year and parents' gender, seems to be consistent with current knowledge about the ways with which children model the educational behavior of their significant adults (parents and teachers). The observed effect suggests that at the end of early school education children's results depend on the level of math anxiety evident in their mothers and teachers; nevertheless, it is likely that this effect is a result of more general mathematical and social factors associated with math anxiety. Future studies on sources of math anxiety and predictors of math achievement should include gender, grade year, math anxiety of teachers, parents and children, as well as cognitive, social, personality- and math-related factors not included in the present study.

Acknowledgements The research was supported by the National Science Centre (Poland; Grant No. 2015/19/N/HS6/00791). I would like to thank all those involved in the project: researchers, management schools, teachers, parents, and pupils.

\section{Compliance with ethical standards}

Conflict of interest The author declares that there is no conflict of interest.

Open Access This article is licensed under a Creative Commons Attribution 4.0 International License, which permits use, sharing, adaptation, distribution and reproduction in any medium or format, as long as you give appropriate credit to the original author(s) and the source, provide a link to the Creative Commons licence, and indicate if changes were made. The images or other third party material in this article are included in the article's Creative Commons licence, unless indicated otherwise in a credit line to the material. If material is not included in the article's Creative Commons licence and your intended use is not permitted by statutory regulation or exceeds the permitted use, you will need to obtain permission directly from the copyright holder. To view a copy of this licence, visit http://creativecommons.org/licen ses/by/4.0/. 


\section{Appendix 1: The Math Anxiety Questionnaire for Adults (MAQA)}

Instruction: Below there is a list of problems related to mathematics. Imagine that you are in a situation in which it is necessary to solve the following problems and determine if you are anxious in these situations by marking the answers as follows: 1-I definitely do not feel anxiety, 2-I generally do not feel anxiety, 3-I feel some anxiety, 4-I definitely feel anxiety

1 - definitely not

2- generally not

3-generally yes

4-definitely yes

1 Calculation of the average level of fuel consumption of a car

2 Calculation of the amount money that should be deposited every month to save 13,500 PLN within 3 years

3 Determine whether the given definition of the number $\pi$ is true: the ratio of the circumference of a circle to its diameter

4 Calculation of how many square meters of bathroom tiles should be purchased

5 The answer to the question of whether a prism can have 37 vertices

6 Give an example of a sequence of natural numbers

$\begin{array}{llll}1 & 2 & 3 & 4\end{array}$

7 Calculation of the surface area of a sphere

8 The answer to the question, in how many ways can 6 people be seated at a table

9 Finding who is the tallest if Tom is taller than Jane, Tom is shorter than Peter, Peter is taller than Monica, and Monica and Jane are the same height

10 Presentation of the geometrical interpretation of the equations $y=-x, y=x+2$

11 Calculation of $12 \%$ less than 215

12 Calculation of the length of a route based on knowledge of the traveled time and average speed

13 Giving an example of the practical application of trigonometric functions

14 Indication of the number of bisectors in a triangle

15 Calculation of average monthly earnings in the case of a 5\% increase

16 Indication of the prime number among the numbers 276, 277, 278, 279, 280

17 Determining the probability that today is Wednesday

18 Dividing the number 10,179 by 13.5 without using a calculator

19 Calculation of the sum $2396 \frac{7}{9}+6725$

\section{Appendix 2: The Math Anxiety Questionnaire for Children (MAQC)}

Instruction: I will ask you some questions related to mathematics. Please, answer "yes", "a little" or "no" to my questions

\begin{tabular}{llr}
1 & Do you like solving mathematical problems? & Yes A little No \\
2 & Do you like being asked questions during math classes? & Yes A little No \\
3 & Do you like to speak about mathematics? & Yes A little No \\
\hline
\end{tabular}


$4 \quad$ Are you nervous when you ask questions about mathematics?

Yes A little No

5 Are you nervous at the thought of making a mistake when solving tasks?

Yes A little No

6 Are you afraid of mathematics?

Yes A little No

7 When you are in math class and the teacher says that you will be discussing a

Yes A little No new topic, are you nervous?

8 When you do your homework in mathematics, are you nervous?

Yes A little No

9 When you start to solve a difficult task, are you nervous?

10 When you solve a task on the blackboard during a math class, do you get stressed?

11 When the teacher explains how to solve a math problem, are you nervous?

Yes A little No

Yes A little No

Yes A little No

12 When you have to ask your teacher for help because you do not know how to

Yes A little No solve a task, are you nervous?

13 Are you nervous when the teacher gives you a lot of addition tasks?

14 Are you nervous when the teacher gives you a lot of subtraction tasks?

Yes A little No

Yes A little No

Items 1-3 are reversed. The MAQC is also available in a revised 12-item version (the last two items have been removed to make the scale universal for a broader age group of children; Szczygieł 2019)

\section{Appendix 3: Additional analysis results}

See Table 7.

Table 7 Gender moderation in math anxiety of adults and math achievement of children

\begin{tabular}{|c|c|c|c|c|c|c|}
\hline & \multicolumn{2}{|l|}{ Mothers } & \multicolumn{2}{|l|}{ Fathers } & \multicolumn{2}{|l|}{ Teachers } \\
\hline & Estimation & $S D$ & Estimation & $S D$ & Estimation & $S D$ \\
\hline \multicolumn{7}{|l|}{ Fixed effects } \\
\hline 1st grade & 0.37 & 0.79 & 1.29 & 0.99 & 4.49 & 4.79 \\
\hline 2nd grade & 0.12 & 0.62 & 0.30 & 0.79 & -0.87 & 1.96 \\
\hline 3rd grade & 0.66 & 0.60 & 0.64 & 1.41 & 0.32 & 1.46 \\
\hline MATH $\times$ gender $(1$ st grade) & 0.21 & 0.53 & 1.14 & 0.80 & -0.99 & 2.47 \\
\hline MATH $\times$ gender $(2$ nd grade $)$ & 0.18 & 0.35 & -0.34 & 0.70 & 0.35 & 0.54 \\
\hline \multirow[t]{2}{*}{ MATH $\times$ gender $(3 r d$ grade $)$} & -0.13 & 0.38 & -0.63 & 1.23 & -0.53 & 0.48 \\
\hline & Variance & $S D$ & Variance & $S D$ & Variance & $S D$ \\
\hline \multicolumn{7}{|l|}{ Random effects } \\
\hline Variance of class effects & 0.95 & 0.97 & 0 & 0 & 0.03 & 0.17 \\
\hline Residual & 0.73 & 0.85 & 0.65 & 0.80 & 0.77 & 0.88 \\
\hline \multicolumn{7}{|l|}{ Model summary } \\
\hline REML & 422.1 & & 102.1 & & 594.9 & \\
\hline$N$ Children & 158 & & 48 & & 222 & \\
\hline$N$ Class & 31 & & 25 & & 29 & \\
\hline
\end{tabular}

Dependent variable: children's math achievement (MATH), independent variable: adults' math anxiety (MAQA)

$* * * p<.001 ; * * p<.01 ; * p<.05$ 


\section{References}

Alexander, L., \& Martray, C. (1989). The development of an abbreviated version of the mathematics anxiety rating scale. Measurement and Evaluation in Counseling and Development, 22, 143-150.

Aslan, D., Oğul, I. G., \& Taş, I. (2013). The impacts of preschool teachers' mathematics anxiety and beliefs on children's mathematics achievement. International Journal of Humanities and Social Science Invention, 2, 45-49.

Beilock, S. L., Gunderson, E. A., Ramirez, G., \& Levine, S. C. (2010). Female teachers' math anxiety affects girls' math achievement. Proceedings of the National Academy of Sciences, 107(5), 18601863. https://doi.org/10.1073/pnas.0910967107.

Berkowitz, T., Schaeffer, M. W., Maloney, E. A., Peterson, L., Gregor, C., Levine, S. C., et al. (2015). Math at home adds up to achievement in school. Science, 350(6257), 196-198.

Bhanot, R. T., \& Jovanovic, J. (2005). Do parents' academic gender stereotypes influence whether they intrude on their children's homework? Sex Roles, 52(9/10), 597-607. https://doi.org/10.1007/s1119 9-005-3728-4.

Blevins-Knabe, B., \& Musun-Miller, L. (1996). Number use at home by children and their parents and its relationship to early mathematical performance. Early Development and Parenting, 5(1), 35-45. https://doi.org/10.1002/(SICI)1099-0917(199603)5:1\%3C35:AID-EDP113\%3E3.0.CO;2-0.

Brunyé, T. T., Mahoney, C. R., Giles, G. E., Rapp, D. N., Taylor, H. A., \& Kanarek, R. B. (2013). Learning to relax: Evaluating four brief interventions for overcoming the negative emotions accompanying math anxiety. Learning and Individual Differences, 27, 1-7. https://doi.org/10.1016/j.lindi f.2013.06.008.

Burton, G. M. (1979). Getting comfortable with mathematics. The Elementary School Journal, 79(3), $129-135$.

Bussey, K., \& Bandura, A. (1984). Gender constancy, social power, and sex-linked modeling. Journal of Personality and Social Psychology, 47, 1242-1302. https://doi.org/10.1037/0022-3514.47.6.1292.

Cannon, J., \& Ginsburg, H. P. (2008). "Doing the math": Maternal beliefs about early mathematics versus language learning. Early Education and Development, 19, 238-260.

Carey, E., Hill, F., Devine, A., \& Szúcs, D. (2017). The modified Abbreviated Math Anxiety Scale: A valid and reliable instrument for use with children. Frontiers in Psychology. https://doi.org/10.3389/ fpsyg.2017.00011.

Cargnelutti, E., Tomasetto, C., \& Passolunghi, M. C. (2016). How is anxiety related to math performance in young students? A longitudinal study of Grade 2 to Grade 3 children. Cognition and Emotion, 31(4), 755-764.

Casad, B. J., Hale, P., \& Wachs, F. L. (2015). Parent-child math anxiety and math-gender stereotypes predict adolescents' math education outcomes. Frontiers in Psychology. https://doi.org/10.3389/fpsyg .2015.01597.

Cheryan, S., Master, A., \& Meltzoff, A. N. (2015). Cultural stereotypes as gatekeepers: Increasing girls' interest in computer science and engineering by diversifying stereotypes. Frontiers in Psychology. https://doi.org/10.3389/fpsyg.2015.00049.

Cipora, K., Szczygieł, M., Willmes, K., \& Nuerk, H. C. (2015). Math anxiety assessment with the Abbreviated Math Anxiety Scale: Applicability and usefulness: Insights from the Polish adaptation. Frontiers in Psychology. https://doi.org/10.3389/fpsyg.2015.01833.

Dotti Sani, G. M., \& Treas, J. (2016). Educational gradients in parents' child-care time across countries, 1965-2012. Journal of Marriage and Family. https://doi.org/10.1111/jomf.12305.

Drudy, S. (2008). Gender balance/gender bias: The teaching profession and the impact of feminisation. Gender and Education, 20(4), 309-323. https://doi.org/10.1080/09540250802190156.

European Parliament and the Council of European Union (2006). Official Journal of the European Union, L 394/10, 962/EC/2006.

Ganley, C. M., \& McGraw, A. L. (2016). The development and validation of a revised version of the math anxiety scale for young children. Frontiers in Psychology. https://doi.org/c10.3389/fpsyg .2016.01181.

Gonzalez, H. B., \& Kuenzi, J. J. (2012). Science, technology, engineering, and mathematics (STEM) education: A primer. Washington, DC: Congressional Research Service.

Goodall, J., \& Johnston-Wilder, S. (2015). Overcoming mathematical helplessness and developing mathematical resilience in parents: An illustrative case study. Creative Education, 6(5), 526-535. 
Gunderson, E. A., \& Levine, S. C. (2011). Some types of parent number talk count more than others: Relations between parents' input and children's cardinal-number knowledge. Developmental Science, 14(5), 1021-1032.

Hadley, K. M., \& Dorward, J. (2011). The relationship among elementary teachers' mathematics anxiety, mathematics instructional practices, and student mathematics achievement. Journal of Curriculum and Instruction, 5(2), 27-44. https://doi.org/10.3776/joci.2011.v5n2p27-44.

Harari, R. R., Vukovic, R. K., \& Bailey, S. P. (2013). Mathematics anxiety in young children: An exploratory study. The Journal of Experimental Education, 81(4), 538-555.

Harper, N. J., \& Daane, C. J. (1998). Causes and reduction of math anxiety in preservice elementary teachers. Action in Teacher Education, 19(4), 29-38. https://doi.org/10.1080/01626620.1998.10462 889.

Hembree, R. (1990). The nature, effects, and relief of mathematics anxiety. Journal for Research in Mathematics Education, 21(1), 33-46. https://doi.org/10.2307/749455.

Hernik, K., Malinowska, K., Piwowarski, R., Przewłocka, J., Smak, M., \& Wichrowski, A. (2014). Polscy nauczyciele i dyrektorzy na tle międzynarodowym. Główne wyniki badania TALIS 2013. [Polish teachers and principals and their counterparts from abroad. Main results of the TALIS 2013 study.]. Warszawa: Instytut Badań Edukacyjnych.

Holmlund, T. D., Lesseig, K., \& Slavit, D. (2018). Making sense of “STEM education” in K-12 contexts. International Journal of STEM Education. https://doi.org/10.1186/s40594-018-0127-2.

Hopko, D. R., Mahadeven, R., Bare, R. L., \& Hunt, M. K. (2003). The Abbreviated Math Anxiety Scale (AMAS): Construction, validity, and reliability. Assessment, 10(2), 178-182.

Jackson, E. (2008). Mathematics anxiety in student teachers. Practitioner Research in Higher Education, 2(1), 36-42.

Jacobsen, C., \& Lehrer, R. (2000). Teacher appropriation and student learning of geometry through design. Journal for Research in Mathematics Education, 31(1), 71-88. https://doi. org/10.2307/749820.

Jameson, M. M. (2014). Contextual factors related to math anxiety in second-grade children. The Journal of Experimental Education, 82(4), 518-536. https://doi.org/10.1080/00220973.2013.813367.

Jamieson, J. P., Mendes, W. B., Blackstock, E., \& Schmader, T. (2010). Turning the knots in your stomach into bows: Reappraising arousal improves performance on the GR. Journal of Experimental Social Psychology, 46(1), 208-212.

Janowicz, J. (2017). Jak statystyka może pomóc w odczytaniu wyników sprawdzianu. [How can statistics help read test results?] Twoja Nowa Era. Magazyn dla nauczycieli matematyki w szkole podstawowej, 17-21. Downloaded from: http://flipbook.nowaera.pl/dokumenty/Flipbook/Magazyn-Spraw dzian-szostoklasisty-mat/Magazyn-Twoja-nowa-era.pdf. 06 Jan 2019.

Jordan, N. C., Kaplan, D., Olah, L. N., \& Locuniak, M. N. (2006). Number sense growth in kindergarten: A longitudinal investigation of children at risk for mathematics difficulties. Child Development, 77(1), 153-175.

Kuznetsova, A., Brockhoff, P. B., \& Christensen, R. H. B. (2017). lmerTest Package: Tests in linear mixed effects models. Journal of Statistical Software, 82(13), 1-26. https://doi.org/10.18637/jss.v082.i13.

Kyttälä, M., \& Lehto, J. E. (2008). Some factors underlying mathematical performance: The role of visuospatial working memory and non-verbal intelligence. European Journal of Psychology of Education, 23(1), 77-94.

Levine, S. C., Suriyakham, L. W., Rowe, M. L., Huttenlocher, J., \& Gunderson, E. A. (2010). What counts in the development of young children's number knowledge? Developmental Psychology, 46(5), 1309-1319.

Li, M., \& Kun, P. (2007). A study on the relationship between temperament and mathematics academic achievement. Research in Mathematical Education, 11(3), 197-207.

Lindskog, M., Winma, A., \& Poom, L. (2017). Individual differences in nonverbal number skills predict math anxiety. Cognition, 159, 156-162.

Lorenzen, J. K. (2017). The effect of instructional strategies on math anxiety and achievement: A mixed methods study of preservice elementary teachers. Dissertation downloaded from: https://aquil a.usm.edu/cgi/viewcontent.cgi?referer=https://www.google.pl/\&httpsredir=1\&article=2464\&conte $\mathrm{xt}=$ dissertations 04 Jan 2019.

Malinowska, K., Smak, M., Walczak, D., \& Wichrowski, A. (2014). Wizerunek nauczycieli. In M. Federowicz, J. Choińska-Mika, \& D. Walczak (Eds.), Raport o stanie edukacji 2013-licza się nauczyciele. [Report on the state of education 2013: Teachers matter.]. Warszawa: Instytut Badań Edukacyjnych. 
Maloney, E. A., \& Beilock, S. L. (2012). Math anxiety: Who has it, why it develops, and how to guard against it. Trends in Cognitive Sciences, 16(8), 404-406. https://doi.org/10.1016/j.tics.2012.06.008.

Maloney, E. A., Ramirez, G., Gunderson, E. A., Levine, S. C., \& Beilock, S. L. (2015). Integrational effects of parents' math anxiety on children's math achievement and anxiety. Psychological Science, 26(9), 1480-1488. https://doi.org/10.1177/0956797615592630.

Malzahn, K. A. (2002). National survey of science and mathematics education: Status of elementary school mathematics teaching. Chapel Hill, NC: Horizon Research.

Mason, J. (1988). Learning and doing mathematics. London: Macmillan.

Maxwell, S., Reynolds, K. J., Lee, E., Subasic, E., \& Bromhead, D. (2017). The impact of school climate and school identification on academic achievement: Multilevel modeling with student and teacher data. Frontiers in Psychology, 8, 2069.

McLeod, B. D., Wood, J. J., \& Weisz, J. R. (2007). Examining the association between parenting and childhood anxiety: A meta-analysis. Clinical Psychology Review, 27(2), 155-172. https://doi. org/10.1016/j.cpr.2006.09.002.

Minarni, B. W., Retnawati, H., \& Nugraheni, T. V. T. (2018). Mathematics teachers' beliefs and its contribution toward teaching practice and student achievement. Journal of Physics: Conference Series. https://doi.org/10.1088/1742-6596/1097/1/012143.

Núñez-Peña, M. I., Guilera, G., \& Suárez-Pellicioni, M. (2014). The Single-Item Math Anxiety Scale: An alternative way of measuring mathematical anxiety. Journal of Psychoeducational Assessment, 32(4), 306-317. https://doi.org/10.1177/0734282913508528.

Park, D., Ramirez, G., \& Beilock, S. L. (2014). The role of expressive writing in math anxiety. Journal of Experimental Psychology, 20(2), 103-111.

Perry, D. G., \& Bussey, K. (1979). The social learning theory of sex differences: Imitation is alive and well. Journal of Personality and Social Psychology, 37(10), 1699-1712. https://doi. org/10.1037/0022-3514.37.10.1699.

Phillipson, S., \& Phillipson, S. N. (2007). Academic expectations, belief of ability, and involvement by parents as predictors of child achievement: A cross-cultural comparison. An International Journal of Experimental Educational Psychology, 27(3), 329-348.

Plake, B. S., \& Parker, C. S. (1982). The development and validation of a revised version of the mathematics anxiety rating scale. Educational and Psychological Measurement, 42(2), 551-557. https:// doi.org/10.1177/001316448204200218.

Ramirez, G., Chang, H., Maloney, E. A., Levine, S. C., \& Beilock, S. L. (2016). On the relationship between math anxiety and math achievement in early elementary school: The role of problem solving strategies. Journal of Experimental Child Psychology, 141, 83-100. https://doi.org/10.1016/j. jecp.2015.07.014.

Ramirez, G., Gunderson, E. A., Levine, S. C., \& Beilock, S. L. (2013). Math anxiety, working memory, and math achievement in early elementary school. Journal of Cognition and Development, 14(2), 187-202.

Ramirez, G., Hooper, S. Y., Kersting, N. B., Ferguson, R., \& Yeager, D. (2018). Teacher math anxiety relates to adolescent students' math achievement. AERA Open, 4(1), 1-13. https://doi. org/10.1177/2332858418756052.

Reynolds, C. R., \& Richmond, B. O. (1978). What I think and feel: A revised measure of children's manifest anxiety. Journal of Abnormal Child Psychology, 6(27), 271-280. https://doi.org/10.1007/BF009 19131.

Richardson, F. C., \& Suinn, R. M. (1972). The Mathematics Anxiety Rating Scale: Psychometric data. Journal of Counseling Psychology, 19(6), 551-554.

Sasanguie, D., Göbel, S. M., Moll, K., Smets, K., \& Reynvoet, B. (2013). Approximate number sense, symbolic number processing, or number-space mapping: What underlies mathematics achievement? Journal of Experimental Child Psychology, 114, 418-431.

Sasser, J. (2010). Elementary teachers' perceived mathematics anxiety and teaching efficacy in relationship to students' mathematics achievement. Electronic theses and dissertations. 1579. Downloaded from: http://stars.library.ucf.edu/etd/1579. 11 Dec 2018.

Simpkins, S. D., Davis-Kean, P. E., \& Eccles, J. S. (2005). Parents' socializing behavior and children's participation in math, science, and computer out-of-school activities. Applied Developmental Science, 9, 14-30. https://doi.org/10.1207/s1532480xads0901_3.

Simpkins, S. D., Davis-Kean, P. E., \& Eccles, J. S. (2006). Math and science motivation: A longitudinal examination of the links between choices and beliefs. Developmental Psychology, 42, 70-83. https ://doi.org/10.1037/0012-1649.42.1.70. 
Sirin, S. R. (2005). Socioeconomic status and academic achievement: A meta-analytic review of research. Review of Educational Research, 75(3), 417-453. https://doi.org/10.3102/00346543075003417.

Soni, A., \& Kumari, S. (2017). The role of parental math anxiety and math attitude in their children's math achievement. International Journal of Science and Mathematics Education, 15(2), 331-347. https://doi.org/10.1007/s10763-015-9687-5.

Sovchic, R. (1996). Teaching mathematics to children. London: Harper Collins College Publishers.

Spielberger, C. D., Strelau, J., Tysarczyk, M., \& Wrześniewski, K. (2011). Podręcznik STAI-Inwentarz Stanu $i$ Cechy Lęku.[Manual for the State-Trait Anxiety Inventory STAI.]. Warszawa: Pracownia Testów Psychologicznych Polskiego Towarzystwa Psychologicznego.

Stark, K. D., \& Laurent, J. (2001). Joint factor analysis of the Children's Depression Inventory and the Revised Children's Manifest Anxiety Scale. Journal of Clinical Child Psychology, 30(4), 552-567. https://doi.org/10.1207/S15374424JCCP3004_11.

Steffens, M. C., Jelenec, P., \& Noack, P. (2010). On the leaky math pipeline: Comparing implicit mathgender stereotypes and math withdrawal in female and male children and adolescents. Journal of Educational Psychology, 102(4), 947-963. https://doi.org/10.1037/a0019920.

Szczygieł, M. (2019). How to measure math anxiety in young children? Psychometric properties of the modified Abbreviated Math Anxiety Scale for Elementary Children (mAMAS-E). Polish Psychological Bulletin, 4(50), 303-315. https://doi.org/10.24425/ppb.2019.131003.

Szczygieł, M., \& Cipora, K. (2016). Lęk przed matematyką przyszłych nauczycieli edukacji przedszkolnej i wczesnoszkolnej. Jak uczyć, kiedy sama się boję? [Math anxiety in future preschool and elementary school teachers. How to teach when I am anxious as well?]. Problemy Wczesnej Edukacji, 2(33), 89-101.

Took, D. J., \& Lindstrom, L. C. (1998). Effectiveness of a mathematics methods course in reducing math anxiety of preservice elementary teachers. School Science and Mathematics, 98(3), 136-139.

Tosto, M. G., Petrill, S. A., Halberda, J., Trzaskowski, M., Tikhomirova, T. N., Bogdanova, O. Y., et al. (2014). Why do we differ in number sense? Evidence from a genetically sensitive investigation. Intelligence, 43, 35-46.

U.S. Department of Education. (2008). Foundations for success: The final report of the National Mathematics Advisory Panel. Washington, DC: U.S. Department of Education.

Vukovic, C. C., Kieffer, M. J., Bailey, S. P., \& Harari, R. R. (2013a). Mathematics anxiety in young children: Concurrent and longitudinal associations with mathematical performance. Contemporary Educational Psychology, 38, 1-10.

Vukovic, R. K., Roberts, S. O., \& Wright, L. G. (2013b). From parental involvement to children's mathematical performance: The role of mathematics anxiety. Early Education and Development, 24, 446-467. https://doi.org/10.1080/10409289.2012.693430.

Widmer, C. C., \& Chavez, A. (1982). Math anxiety and elementary school teachers. Education, 102(3), 272-276.

Wu, S. S., Barth, M., Amin, H., Melcarne, V., \& Menon, V. (2012). Math anxiety in second and third graders and its relation to mathematics achievement. Frontiers in Psychology, 3(162), 1-11. https:// doi.org/10.3389/fpsyg.2012.00162.

Publisher's Note Springer Nature remains neutral with regard to jurisdictional claims in published maps and institutional affiliations.

Dr. Monika Szczygieł works at the Institute of Psychology at the Pedagogical University of Krakow. Her research interests focus on cognitive and emotional predictors of math achievement across the lifespan. She is especially interested in math anxiety, math attitude, and number sense issues. 